\title{
Depression and Anxiety
}

ORIGINAL ARTICLE

\section{Effects of Non-Focused Elf-Emf Treatment on Hrv: Preliminary Study

\author{
Alessandro Greco ${ }^{1^{*}}$ and Anna Destefani ${ }^{2}$
} \\ ${ }^{1}$ M.D. Medical Director APSP, Public Agency for Personal Health Services, Cles, Italy}

${ }^{2}$ Nurse, APSP, Public Agency for Personal Health Services, Cles, Italy

*Corresponding author: Alessandro Greco, M.D. Medical Director APSP, Public Agency for Personal Health Services, Cles, Italy

\begin{abstract}
Background: The Autonomic Nervous System (ANS) is involved in the response to various emotional stimuli like anxiety, stress, and the sense of wellbeing.

As a control system the ANS plays a variety of roles in humans, including regulation of the cardiac function, which can be studied by analyzing heart rate variability (HRV). HRV coherence has been associated with a sense of wellbeing, along with enhanced cognitive, social, and physical performance.

Extremely low frequency electromagnetic fields (ELF-EMF) are used in a variety of clinical areas, however very little is known to date about the functional mechanisms involved in vivo.
\end{abstract}

An interaction with the ANS is one of the possible ways in which the effects of ELF-EMF therapy are modulated in living systems.

In this single-blind study the effects on the ANS of 5 different electromagnetic configurations were analysed by measuring the HRV using a HeartMath $®$ EmWave $₫$ Pro device.

Materials and methods: 46 healthy subjects of 20 to 30 years in age were recruited and divided into two groups (treatment group $\mu$ and control group $\lambda$ ). After measuring the baseline HRV coherence state $(\omega)$ the subjects in group $\mu$ were assessed during administration of 5 different ELF-EMF configurations from a SEQEX® device, all at the same intensity of 20 $\mu \mathrm{T}$ (the name attributed to the configuration is in brackets) for a duration of $3 \mathrm{~min}$. each: $1-3 \mathrm{~Hz}(\delta), 4-8 \mathrm{~Hz}(\theta), 9-13 \mathrm{~Hz}(\alpha)$, $15-29 \mathrm{~Hz}(\beta)$, and $31-56 \mathrm{~Hz}(\mathrm{\gamma})$. The subjects in group $\lambda$ were measured in the same way and the same number of times.

Results: The initial coherence values $\omega$ were comparable between the two groups ( $\mu: 36 \%, \lambda: 36.39 \%$ ). Under the $1-3 \mathrm{~Hz}$ ( $\delta)$ and $15-29 \mathrm{~Hz}(\beta)$ treatment configurations, group $\mu$ had an average HRV coherence of $46.26 \%$ and $47.26 \%$ respectively, while group $\lambda$ had $38.13 \%$ and $37.39 \%$ respectively, representing a significant increase in HRV coherence under treatment $\left(p_{\delta}=0.035\right.$ and $\left.p_{\beta}=0.046\right)$.
Conclusions: The ANS appears to be sensitive in a frequency dependent manner to treatment with ELF-EMF. This is very important, if confirmed in further studies, not only for better understanding the mechanism of action of ELF-EMF on complex biological systems, but more importantly for therapeutic purposes under different levels of psychopathological discomfort like stress and anxiety, as well as for modulating perceived pain and organ dysregulation.

\section{Introduction}

Interest in the interaction between electromagnetic fields and biological systems is constantly growing. Among these, excellent results have been achieved in psychiatrics using transcranial magnetic stimulation [13]. However, very little is known of the effects of electromagnetic fields at low frequencies and intensities (ELF-EMF) on the psychological state of subjects given non focused total body treatment.

This was one of the reasons for the decision to observe the effects of ELF-EMF treatment on the autonomic nervous system (ANS) in order to understand the possible implications of this type of treatment in diverse medical disciplines, not least for controlling anxiety and stress. The ANS is a largely unconscious nervous control system that regulates bodily functions including: pupillary dilation, heart rate, respiration rate, sexual arousal, digestion, and urination [4]. It plays a leading role in triggering and controlling the fight-or-flight response. More specifically, the sympathetic nervous system plays an important role in the development of states of anxiety and stressful situations $[5,6]$. This has been confirmed by various observations of reduced anxiety resulting from surgical inhibition of parts of the

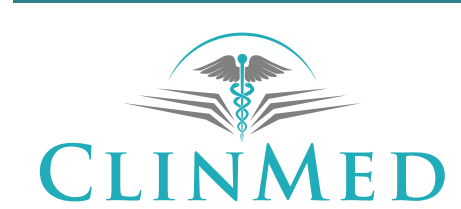

INTERNATIONAL LIBRARY

Citation: Greco A, Destefani A (2018) Late - Life Depression in North Greece: Prevalence and under Detection. Int J Depress Anxiety 1:005

Accepted: October 17, 2018: Published: October 19, 2018

Copyright: (c) 2018 Greco A, et al. This is an open-access article distributed under the terms of the Creative Commons Attribution License, which permits unrestricted use, distribution, and reproduction in any medium, provided the original author and source are credited. 
sympathetic system $[7,8]$. Consequently, the ability to modulate the action of the sympathetic system could be useful for treating extreme moods involving anxiety and stress. It is estimated that a third of the population suffer from anxiety [9], and so the most conservative, non-invasive approach possible, with limited or no side effects, is very desirable.

Heart Rate Variability (HRV) is the physiological phenomenon of variation in the time interval between heartbeats [10]. It is measured as the variation in the beat-to-beat ( $\left.R-R^{\prime}\right)$ interval. In addition to its important prognostic applications in cardiology, as a precursor of mortality following myocardial infarction [11], HRV can also be usefully applied in psychophysiology. Two different components are presents in HRV: high frequency (HF: 0.15-0.4 Hz) and low frequency (LF: 0.04-0.15 $\mathrm{Hz})$. At the actual knowledge $[12,13]$, HF component is generally believed to be the originated by Vagus nerve, while the LF has been thought to be of both sympathetic and vagus origin with more incidence by the sympathetic origin. HRV is closely linked to emotional stimulation, with the HF component of the HRV profile decreasing under extreme time pressure, emotional stress [14], and high levels of anxiety [15], which is probably related to raised attention focus and motor inhibition [15]. HRV is found to be lower in individuals that report higher levels of worry [16]. Individuals suffering from post-traumatic stress disorder (PTSD) typically display a lower HF component, but with a higher LF component. In addition, PTSD patients have been seen to demonstrate no LF or $\mathrm{HF}$ reactivity on recollection of traumatic events [17].

The Polyvagal Theory [18] describes ANS pathways mediating HRV, emphasizing the importance of HRV for assessing vagal outflow to the heart. The theory divides up HRV according to frequency domain characteristics. Emphasis is placed on respiratory sinus arrhythmia, which is transmitted by a neural pathway distinct from other HRV components [19]. Evidence for a polyvagal coronary control mechanism exists in both anatomic [20] and physiological [21] data.

The effects of ELF-EMF on anxiety have already been studied by other authors, with contradictory results: on one hand an increase in the level of anxiety was observed correlated with an increase in oxidative stress in the hypothalamus [22], but other studies have not observed any obvious induction of anxiety in subjects exposed to ELF-EMF $[23,24]$. It is interesting to note that other studies using ELF-EMF have instead shown the effectiveness of the same in reducing oxidative stress [2529] and thus offering therapeutic potential in various clinical areas.

Finally, the correlation between HRV and anxiety was previously investigated in other studies, for both diagnostic [30-32] and therapeutic [3] ends. Cardiac coherence has been associated with a general sense of wellbeing and improved cognitive, social, and physical performance [33]. Some studies on healthy subjects have revealed that during the experience of positive emotions a sine wave-like pattern naturally emerges in the heart rhythms without any conscious changes in breathing $[34,35]$. An increase in HRV coherence correlated with an increase in cerebral activity observed on EEG has been observed in a study on autogenic training [36]. Another study conducted on middle school students with attention deficit hyperactivity disorder showed significant improvements in short and longterm memory, ability to focus, and significant improvements in behaviour both at home and in school [37]. It has also been demonstrated that enhanced HRV coherence [38-40] reduces anxiety and stress levels and strengthens emotional controls [38] among musicians under the effects of stage fright [40].

One study was conducted using heartbeat-evoked potentials, with evidence that using paced breathing at a 10-second rhythm led not only to increased coherence in the rhythms as expected, but also increased the N200 amplitude potential in the EEG heartbeat-evoked potentials, which indicates increased afferent input [41].

This aspect is particularly important as regards, for example, pain therapy. It has been demonstrated that thalamic pain pathways in the spinal cord are inhibited by increases in vagal afferent nerve traffic over normal intrinsic levels $[42,43]$.

In the present study the authors wanted to try and identify a possible modulation effect on HRV through the non focused administration of ELF-EMF at particularly low intensity $(20 \mu \mathrm{T})$, on a voluntary group of healthy subjects.

\section{Materials and Methods}

This single-blind case-control study was conducted within the Public Agency for Personal Health Services (APSP, retirement home) "Santa Maria", located in Cles (TN, Italy).

The study recruited 46 voluntary healthy subjects between 20 and 30 years: 32 women and 14 men, 50\% of the men and women were assigned to group $\mu$, and the remaining $50 \%$ to group $\lambda$.

Throughout the entire period of data acquisition for the study, none of the subjects were informed regarding the nature and purpose of the same: the only information given regarded the type of therapy with ELF-EMF that was to be used (form of treatment, duration, and possible negative effects), and that HRV would be measured. Nobody in the 2 groups was informed whether they belonged to the treatment or control group. The measurements were all taken between 3 p.m. and 6 p.m. in the afternoon.

The SEQEX ${ }^{\circledR}$ device used for the study is produced and distributed by the Italian company S.I.S.T.E.M.I. srl (Trento, Italy), and certified CSQ ISO-13485. These de- 
Table 1: Electromagnetic fields used in the treatment. Each step had a duration of 1 minute.

\begin{tabular}{|l|l|l|l|l|l|}
\hline Configuration & Step & Intensity $(\boldsymbol{\mu t})$ & Frequency $\mathbf{( H z )}$ & Time-On (S) & Time-Off (S) \\
\hline $\boldsymbol{\Delta}$ & 1 & 20 & 1 & 5 & 1 \\
\hline $\boldsymbol{\theta}$ & 2 & 20 & 2 & 5 & 1 \\
\hline & 3 & 20 & 3 & 5 & 1 \\
\hline $\boldsymbol{A}$ & 1 & 20 & 4 & 5 & 1 \\
\hline & 2 & 20 & 6 & 5 & 1 \\
\hline $\boldsymbol{B}$ & 3 & 20 & 8 & 5 & 1 \\
\hline $\boldsymbol{\Gamma}$ & 1 & 20 & 9 & 5 & 1 \\
\hline & 2 & 20 & 11 & 5 & 1 \\
\hline & 3 & 20 & 13 & 5 & 1 \\
\hline & 2 & 20 & 15 & 5 & 1 \\
\hline
\end{tabular}

vices can produce complex electromagnetic fields using an analogical mechanism, across a frequency range of 1 to $80 \mathrm{~Hz}$ and at intensities of 1 to $20 \mu \mathrm{T}$ (ranges in the Adey's Window) [44]. The field parameters are tested by the manufacturers using specialized instrumentation, specifically a Gaussmeter GM 08 produced by the Hirst company. The administration of the electromagnetic field produced by the control unit of the treatment device (on which the electromagnetic field parameters are set), is achieved using a mat containing a Helmholtz coil that generates the ELF-EMF. Patients lie on the mat and receive non-focused total body treatment with the electromagnetic fields set on the control unit.

In this single-blind study, 5 different electromagnetic configurations (brain EEG/MEG frequencies) were tested, each in turn comprising 3 frequency-intensity pairs (called "steps"), with an alternating field emission time-on and time-off (expressed in seconds). In each of the steps a sinusoidal wave with an abundance of harmonics was emitted. The 5 different configurations were labelled with the Greek letters corresponding to the brain waves of the same frequencies $(\delta, \theta, \alpha, \beta, \gamma)$. The characteristics of each configuration are reported in the following Table 1.

Each emitted configuration had a duration of 3 minutes.

The members of group $\mu$ were tested first without administration of any ELF-EMF but with the device switched on (measurement labelled $\omega$ ), and subsequently once for each of the configurations listed in the table. The members of group $\lambda$ were measured in the same way, always with the device switched on but not administering ELF-EMF. All the subjects in the study were thus assessed 6 times.

Treatment was administered using a mat for non-focused total body treatment: the volunteers were measured lying down with their eyes closed. The wooden couch supporting the mat was positioned so that the subjects could not see whether the control unit was operating or otherwise. This, combined with the lack of perception when the field is administered, meant that the subjects were unaware whether they belonged to the treatment or control groups.

Between each two distinct assessments, subjects were requested to stand up and remain standing for 3 minutes away from the treatment mat.

All the treatments were conducted with the same device and in the same environment, the integrative medicine clinic at the APSP Santa Maria, Cles.

\section{HRV}

HRV reflects the synergic action of the two components of the ANS, which in a physiological situation act to maintain cardiac functionality at an optimum state for the subject, and enable suitable responses to external stimuli, with the parasympathetic system reducing the heart rhythm in calm situations, and the sympathetic system increasing it in stressful situations [45].

HRV was measured using the HeartMath ${ }^{\circledR}$ EmWave $^{\circledR}$ Pro device [45-47], which measures HRV with an ear sensor and returns a variability value in real time generated by a hardware/software system (EmWave Pro desktop). The software uses the HRV measurement as a basis to establish a coherence score, calculated as a ratio between the low frequency component of the HRV (00.4-0.15 Hz) divided by the sum of the high frequency $(0.15-0.4 \mathrm{~Hz})$ and very low frequency $(0.01 \backslash 0.04 \mathrm{~Hz})$ [34]. Coherence is expressed with three coloured bars (green indicating a state of high coherence, blue average coherence, and red incoherence) and a numeric percentage value, with the sum of the three coherence states totalling $100 \%$.

The specific algorithms implemented in the software by the developers to transform HRV frequencies into coherence scores are unknown to the researchers.

According to the explanations of the device manufacturers, the coherence scores are based on how symmetrical the wave-like HRV pattern is:

- Red bar: percentage time of no wave-like activity in the HRV wave; 
Table 2: The values from the 6 different measurements from groups $\mu$ (treated with ELF-EMF apart from measurement $\omega$ ) and $\lambda$. Each subject is indicated with their group letter and number. The sex of each subject is also indicated. In the second column the sex of participant is reported $(q=$ female, $\hat{\delta}=$ male $)$.

\begin{tabular}{|c|c|c|c|c|c|c|c|}
\hline & & $\omega$ & $\delta$ & $\theta$ & $\alpha$ & $\beta$ & $\mathbf{Y}$ \\
\hline$\mu 1$ & q & $41.00 \%$ & $41.00 \%$ & $32.00 \%$ & $27.00 \%$ & $42.00 \%$ & $36.00 \%$ \\
\hline$\mu 2$ & $\hat{0}$ & $21.00 \%$ & $58.00 \%$ & $70.00 \%$ & $55.00 \%$ & $76.00 \%$ & $67.00 \%$ \\
\hline$\mu 3$ & $\hat{0}$ & $32.00 \%$ & $39.00 \%$ & $32.00 \%$ & $68.00 \%$ & $48.00 \%$ & $63.00 \%$ \\
\hline$\mu 4$ & 우 & $95.00 \%$ & $85.00 \%$ & $91.00 \%$ & $88.00 \%$ & $94.00 \%$ & $100.00 \%$ \\
\hline$\mu 5$ & 우 & $21.00 \%$ & $0.00 \%$ & $0.00 \%$ & $16.00 \%$ & $0.00 \%$ & $0.00 \%$ \\
\hline$\mu 6$ & o & $33.00 \%$ & $46.00 \%$ & $52.00 \%$ & $36.00 \%$ & $42.00 \%$ & $55.00 \%$ \\
\hline$\mu 7$ & 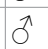 & $93.00 \%$ & $78.00 \%$ & $61.00 \%$ & $78.00 \%$ & $56.00 \%$ & $53.00 \%$ \\
\hline$\mu 8$ & q & $0.00 \%$ & $16.00 \%$ & $30.00 \%$ & $18.00 \%$ & $4.00 \%$ & $19.00 \%$ \\
\hline$\mu 9$ & q & $18.00 \%$ & $34.00 \%$ & $12.00 \%$ & $34.00 \%$ & $45.00 \%$ & $24.00 \%$ \\
\hline$\mu 10$ & 우 & $40.00 \%$ & $54.00 \%$ & $46.00 \%$ & $45.00 \%$ & $32.00 \%$ & $20.00 \%$ \\
\hline$\mu 11$ & q & $40.00 \%$ & $42.00 \%$ & $32.00 \%$ & $27.00 \%$ & $43.00 \%$ & $36.00 \%$ \\
\hline$\mu 12$ & $\hat{\sigma}$ & $21.00 \%$ & $60.00 \%$ & $70.00 \%$ & $54.00 \%$ & $76.00 \%$ & $67.00 \%$ \\
\hline$\mu 13$ & q & $21.00 \%$ & $37.00 \%$ & $46.00 \%$ & $54.00 \%$ & $38.00 \%$ & $40.00 \%$ \\
\hline$\mu 14$ & q & $100.00 \%$ & $72.00 \%$ & $100.00 \%$ & $100.00 \%$ & $100.00 \%$ & $82.00 \%$ \\
\hline$\mu 15$ & 우 & $39.00 \%$ & $50.00 \%$ & $69.00 \%$ & $69.00 \%$ & $59.00 \%$ & $78.00 \%$ \\
\hline$\mu 16$ & q & $15.00 \%$ & $36.00 \%$ & $9.00 \%$ & $6.00 \%$ & $66.00 \%$ & $13.00 \%$ \\
\hline$\mu 17$ & 우 & $12.00 \%$ & $55.00 \%$ & $12.00 \%$ & $18.00 \%$ & $18.00 \%$ & $0.00 \%$ \\
\hline$\mu 18$ & $\hat{0}$ & $88.00 \%$ & $88.00 \%$ & $97.00 \%$ & $81.00 \%$ & $88.00 \%$ & $58.00 \%$ \\
\hline$\mu 19$ & o & $15.00 \%$ & $30.00 \%$ & $33.00 \%$ & $24.00 \%$ & $13.00 \%$ & $24.00 \%$ \\
\hline$\mu 20$ & $\hat{0}$ & $27.00 \%$ & $30.00 \%$ & $6.00 \%$ & $12.00 \%$ & $6.00 \%$ & $26.00 \%$ \\
\hline$\mu 21$ & q & $33.00 \%$ & $18.00 \%$ & $4.00 \%$ & $12.00 \%$ & $52.00 \%$ & $36.00 \%$ \\
\hline$\mu 22$ & q & $13.00 \%$ & $40.00 \%$ & $9.00 \%$ & $10.00 \%$ & $67.00 \%$ & $13.00 \%$ \\
\hline$\mu 23$ & q & $10.00 \%$ & $55.00 \%$ & $12.00 \%$ & $18.00 \%$ & $22.00 \%$ & $0.00 \%$ \\
\hline$\lambda 1$ & q & $41.00 \%$ & $40.00 \%$ & $37.00 \%$ & $33.00 \%$ & $42.00 \%$ & $36.00 \%$ \\
\hline$\lambda 2$ & o & $30.00 \%$ & $38.00 \%$ & $40.00 \%$ & $40.00 \%$ & $35.00 \%$ & $32.00 \%$ \\
\hline$\lambda 3$ & $\hat{0}$ & $32.00 \%$ & $39.00 \%$ & $32.00 \%$ & $29.00 \%$ & $30.00 \%$ & $40.00 \%$ \\
\hline$\lambda 4$ & 우 & $93.00 \%$ & $90.00 \%$ & $91.00 \%$ & $88.00 \%$ & $92.00 \%$ & $100.00 \%$ \\
\hline$\lambda 5$ & q & $21.00 \%$ & $17.00 \%$ & $16.00 \%$ & $20.00 \%$ & $20.00 \%$ & $18.00 \%$ \\
\hline$\lambda 6$ & $\hat{0}$ & $38.00 \%$ & $43.00 \%$ & $46.00 \%$ & $36.00 \%$ & $40.00 \%$ & $50.00 \%$ \\
\hline$\lambda 7$ & $\hat{0}$ & $95.00 \%$ & $83.00 \%$ & $90.00 \%$ & $83.00 \%$ & $81.00 \%$ & $82.00 \%$ \\
\hline$\lambda 8$ & 우 & $0.00 \%$ & $9.00 \%$ & $15.00 \%$ & $15.00 \%$ & $5.00 \%$ & $19.00 \%$ \\
\hline$\lambda 9$ & 우 & $20.00 \%$ & $31.00 \%$ & $16.00 \%$ & $29.00 \%$ & $21.00 \%$ & $18.00 \%$ \\
\hline$\lambda 10$ & ㅇ & $38.00 \%$ & $40.00 \%$ & $46.00 \%$ & $45.00 \%$ & $40.00 \%$ & $20.00 \%$ \\
\hline$\lambda 11$ & 우 & $35.00 \%$ & $39.00 \%$ & $37.00 \%$ & $30.00 \%$ & $37.00 \%$ & $36.00 \%$ \\
\hline$\lambda 12$ & $\hat{0}$ & $28.00 \%$ & $35.00 \%$ & $31.00 \%$ & $40.00 \%$ & $28.00 \%$ & $33.00 \%$ \\
\hline$\lambda 13$ & 우 & $30.00 \%$ & $33.00 \%$ & $31.00 \%$ & $29.00 \%$ & $32.00 \%$ & $32.00 \%$ \\
\hline$\lambda 14$ & 우 & $94.00 \%$ & $94.00 \%$ & $100.00 \%$ & $95.00 \%$ & $95.00 \%$ & $93.00 \%$ \\
\hline$\lambda 15$ & 우 & $37.00 \%$ & $37.00 \%$ & $40.00 \%$ & $38.00 \%$ & $37.00 \%$ & $50.00 \%$ \\
\hline$\lambda 16$ & ㅇ & $18.00 \%$ & $13.00 \%$ & $9.00 \%$ & $20.00 \%$ & $20.00 \%$ & $13.00 \%$ \\
\hline$\lambda 17$ & 우 & $15.00 \%$ & $13.00 \%$ & $12.00 \%$ & $18.00 \%$ & $15.00 \%$ & $19.00 \%$ \\
\hline$\lambda 18$ & $\hat{0}$ & $50.00 \%$ & $53.00 \%$ & $47.00 \%$ & $55.00 \%$ & $50.00 \%$ & $46.00 \%$ \\
\hline$\lambda 19$ & q & $29.00 \%$ & $30.00 \%$ & $33.00 \%$ & $24.00 \%$ & $28.00 \%$ & $30.00 \%$ \\
\hline$\lambda 20$ & o & $29.00 \%$ & $30.00 \%$ & $25.00 \%$ & $38.00 \%$ & $35.00 \%$ & $26.00 \%$ \\
\hline$\lambda 21$ & 우 & $33.00 \%$ & $31.00 \%$ & $40.00 \%$ & $26.00 \%$ & $38.00 \%$ & $36.00 \%$ \\
\hline$\lambda 22$ & ㅇ & $21.00 \%$ & $29.00 \%$ & $30.00 \%$ & $27.00 \%$ & $24.00 \%$ & $13.00 \%$ \\
\hline$\lambda 23$ & q & $10.00 \%$ & $10.00 \%$ & $12.00 \%$ & $18.00 \%$ & $15.00 \%$ & $9.00 \%$ \\
\hline
\end{tabular}

- Blue bar: percentage time of some wave-like activity;

- Green bar: percentage time of marked wave-like activity.

This study considered only the green indicator of high coherence.

\section{Results}

The following results were obtained (Table 2) with the average scores (Table 3) from the 6 measurements
Table 3: The average values obtained from the 6 different measurements for groups $\mu$ (treated with ELF-EMF apart from measurement $\omega$ ) and $\lambda$.

\begin{tabular}{|l|l|l|}
\hline & $\boldsymbol{\mu}$ & $\boldsymbol{\lambda}$ \\
\hline $\boldsymbol{\omega}$ & $36.00 \%$ & $36.39 \%$ \\
\hline $\boldsymbol{\delta}$ & $46.26 \%$ & $38.13 \%$ \\
\hline $\boldsymbol{\theta}$ & $40.22 \%$ & $38.09 \%$ \\
\hline $\boldsymbol{\alpha}$ & $41.30 \%$ & $38.09 \%$ \\
\hline $\boldsymbol{\beta}$ & $47.26 \%$ & $37.39 \%$ \\
\hline $\mathbf{Y}$ & $39.57 \%$ & $37.00 \%$ \\
\hline
\end{tabular}




\section{AVERAGE high hrv coherence VALUES}

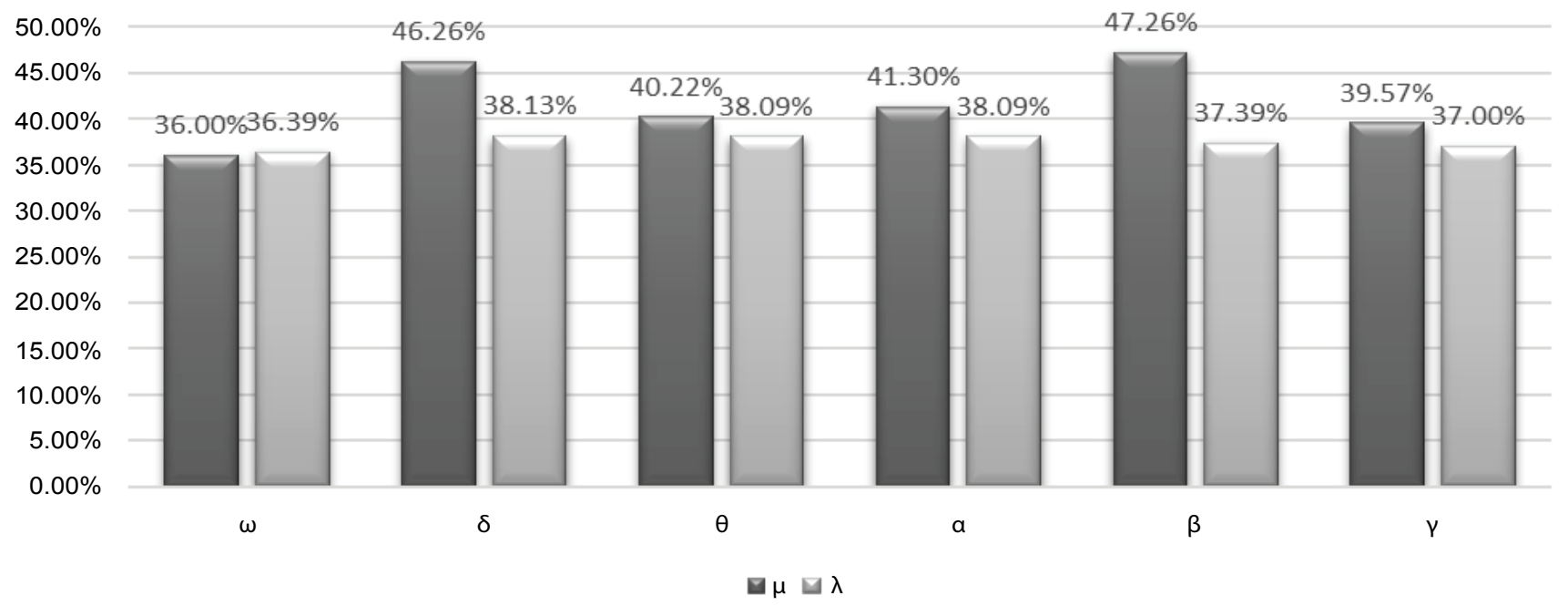

Figure 1: Bar diagram of the average values obtained under the different configurations studied.

from groups $\mu$ and $\lambda$ Figure 1 .

In the initial measurement $\omega$ both groups were essentially the same with a coherence value around $36 \%$.

Administration of ELF-EMF in the $4-8 \mathrm{~Hz}(\theta), 9-13 \mathrm{~Hz}$ $(\alpha)$, and $31-56 \mathrm{~Hz}(\gamma)$ ranges did not produce significant variations in group $\mu$ compared to group $\lambda$.

After administering total body ELF-EMF in the 1-3 $\mathrm{Hz}(\delta)$ range, an increase was recorded in coherence in group $\mu$ with an average of $46.26 \%$ compared to $38.13 \%$ in group $\lambda\left(p_{\delta}=0.035\right)$. Similarly, administration of ELF-EMF in the $15-29 \mathrm{~Hz}(\beta)$ range led to an increase in coherence in group $\mu$ (average $47.26 \%$ ) compared to group $\lambda$ (average $37.39 \%$ ) representing a statistically significant variation in $\mathrm{HRV}\left(\mathrm{p}_{\beta}=0.046\right)$.

\section{Discussion}

In the light of the above regarding coherence levels, and the available literature on the modification of anxiety levels using ELF-EMF [22-24], a single-blind study was designed on healthy subjects between 20 and 30 years in order to investigate how ANS is influenced by non-focused total body therapy. Similar studies was already available in literature [48-53], with results confirming those of the present study, and only one study [54] in which no effects were observed on HRV. Of these studies, three $[48,52,53]$ explored the effects of $16 \mathrm{~Hz}$ EMF ( $\beta$ EEG/MEG frequency), the others [49-51,54] studied the $50 \mathrm{~Hz}$ frequency. Only a study [49] observed different $H R V$ answer with different EMF patterns (same frequency of $16 \mathrm{~Hz}$, but different pulsation frequencies).

According to this bibliographic knowledge, our study is the first in which a frequency-dependent effect on HRV is observed.

The study subjects were all tested after working hours and therefore in an augmented state of tiredness and stress induced by the previous work activity. The measurements were conducted from October 2017 until May 2018. The experimental set-up involved always using the same SEQEX ${ }^{\circledR}$ device with the radiant mat placed on top of a wooden massage couch in order to avoid the development of eddy currents. The couch was positioned in such a way that the subjects could not see whether or not the device was effectively administering ELF-EMF. Since the treatment does not produce any sound or bodily sensation it was impossible for the subjects to understand whether treatment was underway or only simulated. In order to avoid a cumulative effect from the various treatment, after each electromagnetic configuration the subjects were asked to get off the mat for 3 minutes.

The 5 programs tested $(\delta, \theta, \alpha, \beta, \gamma)$ were chosen in order to simulate brain EEG/MEG frequencies. The target of the work was studying how people answer to ELFEMF in range of brain frequencies. The starting hypothesis was investigating if the Nervous System answered to these ELF-EMFs with an adaptative or simulative answer. For this reason, in addition to HRV, in a smaller group EEG also was registered for a parallel study.

As stated earlier, not all the electromagnetic fields used influenced the HRV value, but only those in the 1-3 $\mathrm{Hz}(\delta)$ and $15-29 \mathrm{~Hz}(\beta)$ ranges, which both induced a significant increase in high HRV coherence $\left(p_{\delta}=0.035\right.$ and $\left.p_{\beta}=0.046\right)$, while in the other frequency windows studied the variations were not significant. This result is particularly interesting and surprising if the EEG implications of the two abovementioned rages are considered: $\delta$ waves are predominant in deep sleep, while $\beta$ waves indicate a state of attention. Taking into account the time and context in which the tests were conducted (after work), it could be hypothesised that a presumed condition of accumulated tiredness/stress led to a stronger response to the ELF-EMF that simulated cerebral states of recovery $(\delta)$ and attention $(\beta)$, as if 
indicating two states that were lacking at that precise moment and context.

However, this remains only a hypothesis of the authors. During the study, sample measurements were taken from the two groups of EEC traces, but these have not yet been analysed and will be the subject of a subsequent paper.

It would also be expedient to conduct further investigations during different times of day and week to assess whether the ELF-EMF windows applicable in order to increase the level of HRV coherence effectively depend on external factors (like work activity, circadian rhythm) acting on the individual.

If the latter hypothesis is confirmed, it would also help explain another aspect of the operation of ELF-EMF therapy: part of the therapeutic mechanism obtained using ELF-EMF is probably mediated by the ANS, making it more difficult to formulate a linear model to explain the interaction between ELF-EMF and living systems.

\section{Conclusions}

HRV is seen to be variably sensitive to ELF-EMF, depending on the frequencies used and even under very brief stimulation. Considering the importance of the ANS in the regulation of HRV, an important role is hypothesised for the ANS in the response to ELF-EMF treatment, raising new questions and possible therapeutic applications.

\section{Conflicts of Interest}

Dr. Alessandro Greco declares that he provides scientific consultation in the development of new medical research for the company that manufactures the electromagnetic device used.

The other author declares that no conflicts of interest exist.

\section{References}

1. Gorelick DA, Zangen A, George MS (2014) Transcranial magnetic stimulation in the treatment of substance addiction. Ann N Y Acad Sci 1327: 79-93.

2. Dougall N, Maayan N, Soares-Weiser K, McDermott LM, Mclntosh A (2015) Transcranial magnetic stimulation for schizophrenia. Schizophr Bull 41: 1220-1222.

3. Narayana S, Papanicolaou AC, McGregor A, Boop FA, Wheless JW (2015) Clinical applications of transcranial magnetic stimulation in pediatric neurology. J Child Neurol 30: 1111-1124.

4. Schmidt A, Thews G (1989) Autonomic nervous system. In: Janig W, Human physiology. ( ${ }^{\text {nd }}$ edn), NY: Springer-Verlag, New York, 333-370.

5. Roth WT, Doberenz S, Dietel A, Conrad A, Mueller A, et al. (2008) Sympathetic activation in broadly defined generalized anxiety disorder. J Psychiatr Res 42: 205-212.

6. Hoehn-Saric R, McLeod DR (1988) The peripheral sympathetic nervous system. Its role in normal and pathologic anxiety. Psychiatr Clin North Am 11: 375-386.
7. Pohjavaara P, Telaranta T, Väisänen E (2003) The role of the sympathetic nervous system in anxiety: Is it possible to relieve anxiety with endoscopic sympathetic block? Nord J Psychiatry 57: 55-60.

8. Telaranta T (2003) Psychoneurological applications of endoscopic sympathetic blocks (ESB). Clin Auton Res 13: 120-121.

9. Bandelow B, Michaelis S (2015) Epidemiology of anxiety disorders in the 21st century. Dialogues Clin Neurosci 17: 327-335.

10. Acharya UR, Paul Joseph K, Kannathal N, Lim CM, Suri JS (2006) Heart rate variability: A review. Med Bio Eng Comput 44: 1031-1051.

11. Bigger JT Jr, Fleiss JL, Steinman RC, Rolnitzky LM, Kleiger RE, et al. (1992) Frequency domain measures of heart period variability and mortality after myocardial infarction. Circulation 85: 164-171.

12. Lombardi F, Stein PK (2011) Origin of heart rate variability and turbulence: An appraisal of autonomic modulation of cardiovascular function. Front Physiol 2: 95.

13. Usui H, Nishida $Y$ (2015) Relationship between physical activity and the very low-frequency component of heart rate variability after stroke. J Stroke Cerebrovasc Dis 24: 840843.

14. Nickel P, Nachreiner F (2003) Sensitivity and diagnosticity of the $0.1-\mathrm{Hz}$ component of heart rate variability as an indicator of mental workload. Hum Factors 45: 575-590.

15. Jönsson $P$ (2007) Respiratory sinus arrhythmia as a function of state anxiety in healthy individuals. Int J Psychophysiol 63: 48-54.

16. Brosschot JF, Van Dijk E, Thayer JF (2007) Daily worry is related to low heart rate variability during waking and the subsequent nocturnal sleep period. Int J Psychophysiol 63: 39-47.

17. Cohen H, Kotler M, Matar MA, Kaplan Z, Loewenthal U, et al. (1998) Analysis of heart rate variability in posttraumatic stress disorder patients in response to a trauma-related reminder. Biol Psychiatry 44: 1054-1059.

18. Porges SW (2003) The polyvagal theory: Phylogenetic contributions to social behavior. Physiol Behav 79: 503-513.

19. Porges SW (2007) The polyvagal perspective. Biol Psychol 74: 116-143.

20. Haselton JR, Solomon IC, Motekaitis AM, Kaufman MP (1992) Bronchomotor vagal preganglionic cell bodies in the dog: An anatomic and functional study. J Appl Physiol (1985) 73: 1122-1129.

21. Gatti PJ, Johnson TA, Massari VJ (1996) Can neurons in the nucleus ambiguus selectively regulate cardiac rate and atrio-ventricular conduction? J Auton Nerv Syst 57: 123-127.

22. Djordjevic NZ, Paunović MG, Peulić AS (2017) Anxiety-like behavioural effects of extremely low-frequency electromagnetic field in rats. Environ Sci Pollut Res Int 24: 2169321699.

23. Rostami A, Shahani M, Zarrindast MR, Semnanian S, Rahmati Roudsari M, et al. (2016) Effects of $3 \mathrm{~Hz}$ and $60 \mathrm{~Hz}$ extremely low frequency electromagnetic fields on anxiety-like behaviors, memory retention of passive avoidance and electrophysiological properties of male rats. J Lasers Med Sci 7: 120-125.

24. Lai J, Zhang Y, Liu X, Zhang J, Ruan G, et al. (2016) Effects of extremely low frequency electromagnetic fields $(100 \mu \mathrm{T})$ on behaviors in rats. Neurotoxicology 52: 104-113. 
25. Balind SR, Selakovic V, Radenovic L, Prolic Z, Janac B (2014) Extremely low frequency magnetic field $(50 \mathrm{~Hz}, 0.5$ $\mathrm{mT}$ ) reduces oxidative stress in the brain of gerbils submitted to global cerebral ischemia. PLoS One 9: e88921.

26. Morabito C, Rovetta F, Bizzarri M, Mazzoleni G, Fanò G, et al. (2010) Modulation of redox status and calcium handling by extremely low frequency electromagnetic fields in C2C12 muscle cells: A real-time, single-cell approach. Free Radic Biol Med 48: 579-589.

27. Rossi E, Corsetti MT, Sukkar S, Poggi C (2007) Extremely low frequency electromagnetic fields prevent chemotherapy induced myelotoxicity. Electromagn Biol Med 26: 277281.

28. Raggi F, Vallesi G, Rufini S, Gizzi S, Ercolani E, et al. (2008) ELF magnetic therapy and oxidative balance. Electromagn Biol Med 27: 325-339.

29. Vallesi G, Raggi F, Rufini S, Gizzi S, Ercolani E, et al. (2007) Effects of cyclotronic ion resonance on human metabolic processes: A clinical trial and one case report. Electromagn Biol Med 26: 283-288.

30. Chalmers JA, Quintana DS, Abbott MJ, Kemp AH (2014) Anxiety disorders are associated with reduced heart rate variability: A meta-analysis. Front Psychiatry 5: 80.

31. Gorman JM, Sloan RP (2000) Heart rate variability in depressive and anxiety disorders. Am Heart J 140: 77-83.

32. White EK, Groeneveld KM, Tittle RK, Bolhuis NA, Martin RE, et al. (2017) Combined neurofeedback and heart rate variability training for individuals with symptoms of anxiety and depression: A retrospective study. NeuroRegulation 4: 37-55.

33. McCraty R, Shaffer F (2015) Heart rate variability: New perspectives on physiological mechanisms, assessment of self-regulatory capacity, and health risk. Glob Adv Health Med 4: 46-61.

34. McCraty R, Atkinson M, Tiller WA, Rein G, Watkins AD (1995) The effects of emotions on short-term power spectrum analysis of heart rate variability. Am $\mathrm{J}$ Cardiol 76: 1089-1093.

35. Tiller WA, McCraty R, Atkinson M (1996) Cardiac coherence: $A$ new, noninvasive measure of autonomic nervous system order. Altern Ther Health Med 2: 52-65.

36. Kim DK, Lee KM, Kim J, Whang MC, Kang SW (2013) Dynamic correlations between heart and brain rhythm during Autogenic meditation. Front Hum Neurosci 7: 414.

37. Lloyd A, Brett D, Wesnes K (2010) Coherence training in children with attention-deficit hyperactivity disorder: Cognitive functions and behavioral changes. Altern Ther Health Med 16: 34-42.

38. Bradley RT, McCraty R, Atkinson M, Tomasino D, Daugherty $A$, et al. (2010) Emotion self-regulation, psychophysiological coherence, and test anxiety: Results from an experiment using electrophysiological measures. Appl Psychophysiol Biofeedback 35: 261-283.

39. Lee J, Kim JK, Wachholtz A (2016) The benefit of heart rate variability biofeedback and relaxation training in reducing trait anxiety. Hanguk Simni Hakhoe Chi Kongang 20: 391-408.
40. Wells R, Outhred T, Heathers JA, Quintana DS, Kemp AH (2012) Matter over mind: A randomised-controlled trial of single-session biofeedback training on performance anxiety and heart rate variability in musicians. PLoS One 7: e46597.

41. MacKinnon S, Gevirtz R, McCraty R, Brown M (2013) Utilizing heartbeat evoked potentials to identify cardiac regulation of vagal afferents during emotion and resonant breathing. Appl Psychophysiol Biofeedback 38: 241-255.

42. Foreman R (1997) Organization of visceral input. Yaksh TL, Lynch C, Zapol WM, Maze M, Biebuyck JF, Saidman LJ, Anesthesia: Biologic foundations. Philadelphia: Lippincott-Raven Publishers, 663-683.

43. Foreman RD (1994) Vagal afferent modulation of cardiac pain. Levey MN, Schwartz PJ, Vagal control of the heart: Experimental basis and clinical implications. Armonk, New York: Futura Publishing Co, 345-368.

44. Adey WR (1993) Whispering between cells: Electromagnetic fields and regulatory mechanism in tissue. Frontier Perspect 3: 21-25.

45. McCraty C, Atkinson M, Tomasino D, Bradley RT (2009) The coherent heart Heart-brain interactions, psychophysiological coherence, and the emergence of system-wide order. Integral Review 5: 10-115.

46. Soares AHG, Farah BQ, Cucato GG, Bastos CJA, Christofaro DGD, et al. (2016) Is the algorithm used to process heart rate variability data clinically relevant? Analysis in male adolescents. Einstein (Sao Paulo) 14: 196-201.

47. McCraty R (2015) Heart-brain neurodynamics: The making of emotion. 76-110.

48. Fang Q, Mahmoud SS, Yan J, Li H (2016) an investigation on the effect of extremely low frequency pulsed electromagnetic fields on human electrocardiograms (ECGs). Int $\mathrm{J}$ Environ Res Public Health 13.

49. Baldi E, Baldi C, Lithgow BJ (2007) A pilot investigation of the effects of extremely low frequency pulsed electromagnetic fields on human's heart rate variability. Bioelectromagnetics 28: 64-68.

50. Tabor Z, Michalski J, Rokita E (2004) Influence of $50 \mathrm{~Hz}$ magnetic field on human heart rate variability: Linear and nonlinear analysis. Bioelectromagnetics 25: 474-480.

51. Sastre A, Graham C, Cook MR (2000) Brain frequency magnetic fields alter cardiac autonomic control mechanisms. Clin Neurophysiol 111: 1942-1948.

52. Griefahn B, Kunemund C, Blaszkewicz M, Golka K, Degen $\mathrm{G}$ (2002) Experiments on effects of an intermittent $16.7-\mathrm{Hz}$ magnetic field on salivary melatonin concentrations, rectal temperature and heart rate in humans. Int Arch Occup Environ Health 75: 171-178.

53. Borjanovic SS, Jankovic SM, Pejovic Z (2005) ECG changes in humans exposed to $50 \mathrm{~Hz}$ magnetic fields. J Occup Health 47: 391-396.

54. Sait ML, Wood AW, Kirsner RL (2006) Effects of $50 \mathrm{~Hz}$ magnetic field exposure on human heart rate variability with passive tilting. Physiol Meas 27: 73-83. 